\title{
EDITORIAL
}

\section{LAS REVISTAS DEPREDADORAS, UNA NUEVA EPIDEMIA CIENTÍFICA}

\author{
PREDATORY JOURNAL, A NEW SCIENTIFIC EPIDEMIA \\ Dr. EVARISTO JimÉNEZ-CONTRERAS \\ JuAn José JiMÉnEZ-Segura, GRAduAdo en DocumentaCión
}

\begin{abstract}
Departamento Información y Comunicación, Facultad de Comunicación y Documentación, Grupo de investigación "Evaluación de la Ciencia y de la Comunicación Científica. EC3". Universidad de Granada, España. E-mail: evaristo@ugr.es, juanjosejimenez@correo.ugr.es
\end{abstract}

En un acto académico reciente en mi universidad se presentó un informe sobre la creciente amenaza de las denominadas "predatory journals" en el mundo de la investigación. La primera sorpresa y la causa que anima este editorial fue constatar el generalizado desconocimiento de este fenómeno entre los investigadores, incluso expertos, lo que significa que están expuestos a caer, ellos y sus publicaciones, en manos de editoriales desaprensivas que se cobijan bajo el movimiento Open Access (OA) pero que son, si se quiere decir así, el "dark side" de este movimiento. Por ello presentamos una descripción y aviso sobre la magnitud del fenómeno y algún consejo para precaverse del mismo.

El movimiento OA, como es bien conocido, surge en torno al 2000 (1), como una respuesta a las prácticas comerciales abusivas de conglomerados editoriales que venían aprovechando su posición dominante para aumentar los precios de sus productos, especialmente las publicaciones periódicas, de forma desproporcionada y forzaban a las entidades académicas (universidades y similares) a desarrollar políticas de compra que convenían a estas empresas pero no tanto a las instituciones. El movimiento OA pretendía romper ese monopolio, garantizando un acceso irrestricto de los resultados de investigación a todos los investigadores y eliminar a los intermediarios (los grupos editoriales), trasladando los costes de edición directamente desde los autores a las revistas. El pago por publicar se presentaba así como una solución a esta situación de oligopolio empresarial, el éxito de revistas como Plos One avalaban la fórmula y un notable incremento de la visibilidad de las publicaciones abonadas a esta fórmula aparecía como un aval adicional importante a esta política (2).

Para los investigadores y defensores del OA la idea era conseguir el acceso abierto 
a los resultados de la investigación, reducir costes eliminando intermediarios, y adicionalmente favorecer las capacidades investigadoras de los países menos desarrollados, dado que éstos podrían acceder a la misma sin pagar los costes de las suscripciones a los proveedores. Digamos que dichos costes repercutirían en los grupos de investigación más "pudientes" a través de los llamados cargos por publicación (Article Processing Charges, APCs). Aunque, evidentemente, si estos grupos querían publicar deberían pagar igualmente; la suma-resta de estas operaciones aparecía sin embargo como favorable para los países menos desarrollados.

El movimiento OA ha tenido una acogida entusiasta entre los investigadores, bibliotecarios e incluso los políticos, pero nosotros no vamos a detenernos ahora en los pros y contras de esta política, sólo en una consecuencia no deseada, aunque en cierta forma inevitable, de este nuevo estado de cosas al que se enfrentan los investigadores a la hora de publicar: la aparición de ventajistas dispuestos a aprovecharse de la coyuntura y de la ingenuidad de muchos de los implicados.

Fue a partir de 2010 cuando un bibliotecario llamado Jeffrey Beall, de la biblioteca Auraria de la Universidad de Colorado-Denver, publicó las primeras advertencias sobre la aparición de revistas que dicen pertenecer al movimiento OA, pero que, de hecho, son poco menos que timos científicos. A estas revistas y a sus editoriales las bautizó con el significativo calificativo de predatory (3). Este mismo autor lanza en 2011 una página denominada "Scholarly Open Access" (https://scholarlyoa. $\mathrm{com} /$ publishers/) en la que listaba las editoriales que bajo la pantalla de la publicación OA, es decir trasladando los costes de la publicación a los autores, lo único que hacían era saquear a éstos sin ejercer ninguna de las labores que se suponen que una revista científica debe desarrollar: dar difusión a los originales, garantizar su preservación, y muy especialmente realizar la evaluación de los originales por pares.

A pesar de todo la posibilidad de dar salida a la investigación a través de las revistas OA (o de sus versiones parásitas fraudulentas) no hubiera sido tan atractiva y letal para los investigadores si no se hubiese añadido otro agravante a esta situación. Esta circunstancia sobrevenida en los últimos años ha sido la instauración en el entorno académico de políticas que han enfrentado a muchos investigadores, casi de la noche a la mañana, a la necesidad de aumentar sus curricula con publicaciones en revistas internacionales porque así se lo exigían las instituciones (agencias, ministerios, etc.) ante las que debían rendir cuentas y además su progresión académica, y con frecuencia una parte significativa de su salario se vinculaba a la capacidad de publicar en revistas internacionales (muchos países latinoamericanos, asiáticos, etc., se han adherido a estas políticas importadas de los países más desarrollados).

Estos son los elementos que se han combinado desencadenando lo que creemos no exagerado calificar como epidemia: el movimiento OA, que no es evidente- 
mente responsable de esta plaga, una inédita presión por publicar sobre muchos investigadores e instituciones y un creciente número de "editores" dispuestos a aprovechar esta coyuntura para vender un producto falso que se hace pasar por revista académica adscrita al movimiento OA pero que, en realidad, sólo pretende hacerse con una parte del pastel económico que estas revistas atraen, a costa de investigadores ignorantes del peligro y atraídos por las perspectivas de publicar rápidamente, sin grandes dificultades y a un precio asequible. En todo este fraude hay también una parte de connivencia de los autores como se puede ver.

¿Cómo se puede reconocer a una de estas revistas depredadoras? La lista Beall contiene alrededor de 50 criterios que sirven tanto para definir al editor como a la revista predator, que se pueden agrupar en grandes apartados:

1. Editor y personal: el editor en jefe se identifica como el editor en todas o en la mayor parte de las revistas publicadas por la organización. Las revistas tienen un número insuficiente de miembros en el comité editorial (2 ó 3 miembros) o tienen un comité formado por investigadores de cierto recorrido pero a los que eximen de ninguna contribución en la revista excepto del uso de sus nombres y/o fotografías. Además, no hay prácticamente diversidad geográfica en este equipo editorial, lo cual es especialmente llamativo en revistas que pretenden ser internacionales en el ámbito.

2. Gestión de negocios: el editor muestra falta de transparencia en sus operaciones de edición. No tiene pólizas o prácticas para la preservación digital, lo que significa que si la revista cesa sus operaciones, todo el contenido desaparece de internet (lo cual sucede con cierta frecuencia). Además, comienza sus operaciones con un gran número de revistas, normalmente usando un diseño común para todas. Proporciona poca información, sobre todo la relacionada con el pago por parte del autor, ofreciéndose a publicar el documento del autor y después enviándole un documento "sorpresa" con los cargos asociados a la publicación (suelen tener además una actitud agresiva, solicitando originales a los autores una vez que localizan sus correos electrónicos).

3. Integridad: el editor dedica insuficientes recursos para prevenir y eliminar las malas conductas de los autores, hasta el punto de que las revistas sufren repetidos casos de plagio, incluso propios y de manipulación de imágenes.

4. El nombre de la revista: que suele ser incongruente con la misión de la misma y no refleja su origen, por ejemplo, revistas con las palabras "canadiense", "americana", "europea" o "sueca" en sus nombres, en las que ni el editor ni ninguna institución afiliada aparece relacionada con estos países. Estos anzuelos funcionan para atraer a autores que eligen una revista u otra teniendo en cuenta la localización de la misma, prefiriendo las situadas en los Estados Unidos o en Europa Occidental por su mejor imagen. 
5. Visibilidad: el editor declara habitualmente que sus revistas están indexadas en diversas bases de datos y tienen un factor de impacto, pero en las bases de datos no hay rastro de las mismas, de hecho la mitad ni siquiera tienen ISSN, y muchos de los que aparecen en ellas son ficticios. Tampoco los impactos han sido asignados por la genuina Thomson Reuters sino por otras empresas cuyas marcas recuerdan sospechosamente a la original (Global Impact Factor, International Scientific Indexing (ISI), etc.).

La página de Beall en este momento tiene censadas más de 16.000 revistas. Sólo entre abril de 2015 y mayo de 2016, fechas en las que se realizaron recuentos de las editoriales para el mencionado informe, su número pasó de 749 a 1.058, un incremento de más del $40 \%$ en un año (la última consulta realizada en agosto de este año eleva la lista a 1.158), con el agravante de que el número de enlaces no operativos se acercaba al centenar, lo que implica que si algún autor había depositado sus originales en estas páginas caídas, en la práctica sus trabajos no estaban ya accesibles. Recientemente Beall ha incluido también un listado de bases de datos en internet que proporciona índices de impacto fraudulentos, casi una cincuentena.

El tema y los peligros de las revistas depredadoras no se han planteado hasta hace muy poco en la literatura internacional. El primer trabajo detectado remonta apenas a 2013 y es publicado no casualmente por un autor hindú, señalando cómo las regulaciones exigidas al profesorado de las universidades hindúes para obtener sus acreditaciones, emanadas de la UGC (University Grant Comission), han sido determinantes en el florecimiento de estas revistas (4).

Desde ese año el número de trabajos ha aumentado rápidamente, desde este primero y único en 2013 hasta 20 en 2015 (según la Web of Science). Muchos de estos trabajos, sobre todo los primeros, son denuncias de la nueva amenaza (5), acompañadas con calificativos bastante contundentes: "These unscrupulous publishers are exploiting the open-access (OA) model by corrupting the peer-review process, which is often absent or minimal". Este mismo autor añade: "Even experienced scientists have been duped into joining the editorial boards of bogus journals".

En general los estudios más empíricos sobre estas revistas se han centrado en sus políticas de cobros, orientadas a los mercados locales y de países no desarrollados y a sus (cabría decir inexistentes) protocolos de evaluación para demostrar que las revistas de este tipo no los practican o lo hacen de forma muy superficial con la simple intención de aparentar que se cumplen ciertas normas $(6,7)$.

El perfil de una revista de este tipo es más o menos el siguiente: sede principal en algún país asiático, principalmente la India, aunque muchos tienen una sede electrónica en los Estados Unidos. Las temáticas más habituales son generalistas, es decir la editorial oferta revistas de multitud de especialidades, seguidas de las editoriales dedicadas sólo a Medicina (también con multitud de subespecialida- 
des), Ciencias experimentales o Ingeniería. Las editoriales dedicadas a las Ciencias Sociales son muy escasas y las dedicadas a Humanidades prácticamente inexistentes (recuérdese que en la práctica la totalidad de las revistas de este ámbito son gratuitas, por lo que las oportunidades de negocio son nulas).

Respecto a las "tarifas", otro síntoma de que se trata de una revista depredadora es que resulta difícil con frecuencia averiguar qué hay que pagar y cuánto. En un estudio realizado el rango de cobros va desde 50 a 1.500 USD, pero casi el 50\% se sitúa entre 100 y 400 USD. En general las editoriales situadas en países menos desarrollados tienden a cobrar menos, lo que confirma que trabajan primordialmente para el mercado local y para países del mismo entorno.

Uno de los procedimientos de legitimación que las revistas emplean, y otro de los peligros a los que se enfrenta el investigador, es formar comités científicos internacionales, que se han constituido por el sistema de enviar cientos de invitaciones hasta encontrar a algunos investigadores más incautos o deseosos de formar parte de un supuesto "international journal" de su especialidad, a los que además no les imponen ningún tipo de obligación a cambio de ceder su nombre e imagen. Aún así es significativo que los países con mayor presencia en los comités de estas revistas sean en orden decreciente: India, Estados Unidos, China, Turquía e Irán. Significativamente la mayor desproporción entre el peso real del país, tomando como referencia su posición en el Scientific Journal Ranking (SJR) (que podemos aceptar como un ranking de países académicamente serio), y su presencia en los comités de las revistas depredadoras es la de los países africanos, especialmente Nigeria, seguida de la India. Mientras que en el extremo opuesto (menor presencia en estas revistas) están los países de Europa Occidental, donde el fenómeno parece tener menos virulencia.

En resumen, este editorial no es más que un llamado de alerta a los investigadores para que no se dejen seducir por cantos de sirena de editoriales que les invitan a formar parte de sus comités, o a enviar sus originales a revistas que declaran ser integrantes del movimiento Open Access, prometen rápidas publicaciones y visibilidad internacional... por un módico precio. Antes que nada comprueben si no están incluidas en la lista de Beall.

\section{REFERENCIAS}

1. Shearer K. BioMed Central: An Alternative to Scholarly Publishing. CARL/ ABRC Backgrounder Series $\mathrm{N}^{\circ} 4$ [Internet]. Ottawa: Canadian Association of Research Libraries; 2002 [citado 26 ago 2016]. Disponible en: http://web.archive.org/web/20110927024749/http://www.carl-abrc.ca/projects/scholarly_communication/pdf/biomed_central-e.PDF 
2. Harnad S, Brody T. Comparing the Impact of Open Access (OA) vs. Non-OA articles in the same journals. D-Lib Magazine. 2004; 10(6).

3. Beall J. "Predatory” Open-Access Scholarly Publishers. The Charleston Advisor. 2010; 11(4): 10-17.

4. Raju NV. How does UGC identify predatory journals? Current Science. 2013; 104(11): 1461-1462.

5. Bartholomew RE. Science for sale: the rise of predatory journals. J R Soc Med. 2014; 107(10): 384-385. DOI: 10.1177/0141076814548526

6. Bohannon J. Who's afraid of peer review? Science. 2013; 342(6154): 60-5. http:// doi.org/10.1126/science.342.6154.60

7. Xia J, Harmon JL, Connolly KG, Donnelly RM, Anderson MR, Howard HA. Who publishes in "predatory" journals? J Assoc Inf Sci Technol. 2015; 66(7): 1406-1417. http://doi.org/10.1002/asi.23265 